\title{
A comparative evaluation of the analytical performances of Capillarys 2 Flex Piercing, Tosoh HLC-723 G8, Premier Hb9210, and Roche Cobas c501 Tina-quant Gen 2 analyzers for $\mathrm{HbA}_{1 \mathrm{c}}$ determination
}

Xiaobin Wu, Yan Chao, Zemin Wan, Yunxiu Wang, Yan Ma, Peifeng Ke, Xinzhong Wu, Jianhua Xu, Junhua Zhuang, Xianzhang Huang* Department of Laboratory Science, Second Affiliated Hospital of Guangzhou University of Chinese Medicine, Guangdong, China

*Corresponding author: huangxz020@163.com

\begin{abstract}
Introduction: Haemoglobin $\mathrm{A}_{1 \mathrm{c}}\left(\mathrm{HbA}_{1 \mathrm{c}}\right)$ is widely used in the management of diabetes. Therefore, the reliability and comparability among different analytical methods for its detection have become very important.

Materials and methods: A comparative evaluation of the analytical performances (precision, linearity, accuracy, method comparison, and interferences including bilirubin, triglyceride, cholesterol, labile $\mathrm{HbA}_{1 \mathrm{c}}\left(\mathrm{LA}_{1 \mathrm{c}}\right.$ ), vitamin $\mathrm{C}$, aspirin, fetal haemoglobin ( $\left.\mathrm{HbF}\right)$, and haemoglobin $\mathrm{E}(\mathrm{Hb} \mathrm{E})$ ) were performed on Capillarys 2 Flex Piercing (Capillarys 2FP) (Sebia, France), Tosoh HLC-723 G8 (Tosoh G8) (Tosoh, Japan), Premier Hb9210 (Trinity Biotech, Ireland) and Roche Cobas 501 (Roche c501) (Roche Diagnostics, Germany).

Results: A good precision was shown at both low and high $\mathrm{HbA}_{1 \mathrm{c}}$ levels on all four systems, with all individual CVs below $2 \%$ (IFCC units) or 1.5\% (NGSP units). Linearity analysis for each analyzer had achieved a good correlation coefficient $\left(\mathrm{R}^{2}>0.99\right)$ over the entire range tested. The analytical bias of the four systems against the IFCC targets was less than $\pm 6 \%$ (NGSP units), indicating a good accuracy. Method comparison showed a great correlation and agreement between methods. Very high levels of triglycerides and cholesterol ( $\geq 15.28$ and $\geq 8.72 \mathrm{mmol} / \mathrm{L}$, respectively) led to falsely low $\mathrm{HbA}_{1 \mathrm{C}}$ concentrations on Roche c501. Elevated $\mathrm{HbF}$ induced false $\mathrm{HbA}_{1 \mathrm{c}}$ detection on Capillarys 2FP ( $\left.>10 \%\right)$, Tosoh G8 (> 30\%), Premier Hb9210 (> 15\%), and Roche c501 (> 5\%). On Tosoh G8, HbE induced an extra peak on chromatogram, and significantly lower results were reported.

Conclusions: The four $\mathrm{HbA}_{1 \mathrm{c}}$ methods commonly used with commercial analyzers showed a good reliability and comparability, although some interference may falsely alter the result.
\end{abstract}

Keywords: Haemoglobin $\mathrm{A}_{1 c^{\prime}}$ capillary electrophoresis (CE); high-performance liquid chromatography (HPLC); affinity chromatography; immunoassay

\section{Introduction}

Haemoglobin $A_{1 c}\left(\mathrm{HbA}_{1 c}\right)$, a major portion of the glycated haemoglobins, is formed by a nonenzymatic interaction of glucose with the $\mathrm{N}$-terminal valine residue of the $\mathrm{HbA} \beta$ chain in two basic steps: first, glucose binds reversibly to haemoglobin $(\mathrm{Hb})$ as an aldimine Schiff base (an intermediate, termed labile $\mathrm{HbA}_{1 \mathrm{c}}\left(\mathrm{LA}_{1 \mathrm{c}}\right)$, or $\mathrm{Hb}$ pre- $\left.\mathrm{A}_{1 \mathrm{c}}\right)$; and then, the aldimine is transformed via an Amadori rearrangement into an irreversible ketoamine (1). Because $\mathrm{HbA}_{1 \mathrm{c}}$ reflects a mean blood glucose level over 2-3 months (normal lifespan of red blood cells) with a low short-term variability, it is widely used in the management of diabetes to monitor long-term glycemic control and to assess the risk of developing complications $(2,3)$. In the last several years, the American Diabetes Association (ADA) and other major organizations have endorsed the use of $\mathrm{HbA}_{1 \mathrm{c}}$ determination for diabetes screening and have suggested the value of $6.5 \%(48 \mathrm{mmol} / \mathrm{mol})$ as a diagnostic cut-off $(4,5)$.

Analytical methods for $\mathrm{HbA}_{1 c}$ quantification have been available since the 1970s. Presently, a num- 
ber of methods are used: the capillary electrophoresis (CE) or ion-exchange chromatography method separates and determines $\mathrm{HbA}_{1 \mathrm{c}}$ from other $\mathrm{Hb}$ fractions based on charge differences; the boronate affinity chromatography method separates and quantifies glycated $\mathrm{Hb}$ from the nonglycated $\mathrm{Hb}$ based on the cis-diol group; and the immunoassay method uses antibodies to recognize the structure of the $\mathrm{N}$-terminal glycated amino acids of the $\mathrm{Hb} \beta$ chain for quantification (6). As different methods for $\mathrm{HbA}_{1 \mathrm{c}}$ determination exhibit different characteristics and performances, over the past years, major efforts have been made by the National Glycohemoglobin Standardization Program (NGSP) and the International Federation of Clinical Chemistry and Laboratory Medicine (IFCC) to standardize $\mathrm{HbA}_{1 \mathrm{c}}$ determination. The IFCC reference system has been defined as the only valid anchor to implement a standardization of the measurement (7). However, variability between methods is still observed in the presence of other members of the haemoglobin family (e.g., $L_{1 A^{\prime}}$ fetal haemoglobin $(\mathrm{HbF})$, and variants) or interfering substances in the samples (e.g., bilirubin, triglyceride, cholesterol, and drugs) (8-13).

Due to clinical requirements and management demands, the reliability of different methods used to measure $\mathrm{HbA}_{1 \mathrm{c}}$ and their potential interchange ability represent a key feature in clinical practice. Therefore, the aim of this study was to evaluate the performances (precision, linearity, and accuracy), concordance (method comparison), and influence of the most frequent analytical interferences (bilirubin, triglyceride, cholesterol, $\mathrm{LA}_{1 c^{\prime}}$ vitamin $\mathrm{C}$, aspirin, $\mathrm{HbF}$, and haemoglobin $\mathrm{E}(\mathrm{HbE})$ ) using the four systems. The results of this study will be helpful for laboratorians to be aware of the limitations of the methods and to select the appropriate one that is less likely to have interference.

\section{Materials and methods}

\section{Analyzers}

Four systems were used to obtain $\mathrm{HbA}_{1 c}$ measurements: a Capillarys 2 Flex Piercing (Capillarys 2FP) (Sebia, France) CE system, a Tosoh HLC-723 G8 (To- soh G8) (Tosoh, Japan) (variant-mode) ion-exchange high-performance liquid chromatography (HPLC) system, a Premier Hb9210 (Trinity Biotech, Ireland) boronate affinity HPLC system, and a turbidimetric inhibition immunoassay (TINIA) system using the Tina-quant Gen2 assay on a Roche Cobas c501 (Roche c501) (Roche Diagnostics, Germany) instrument. All four systems were certified by the IFCC and NGSP.

The analyzers as well as the associated reagents used for this evaluation were used according to the manufacturers' instructions and calibrated only once according to their routine standard operating procedures prior to any sample analysis. Internal quality controls (both low and high levels) supplied by the manufacturers and purchased from Bio-Rad Laboratories, Hercules, CA, USA (740 Diabetes Controls, lot: 33861/33862) were measured along with the samples on the same day during this study. The same assessment test by the four systems was carried out on the same day by the same technician in our laboratory. The same assessment test by one system was carried out using the same batch accompanied with the same controls.

\section{Samples}

Whole blood samples $(\mathrm{N}=157)$ and umbilical cord blood $(\mathrm{N}=1)$ were collected in EDTA-containing tubes $(2.0 \mathrm{~mL}$, BD Diagnostics, Franklin Lakes, NJ, USA) and kept at $4 \pm 2{ }^{\circ} \mathrm{C}$ to be analyzed within 24 h. For precision, method comparison, and analytical interference of $\mathrm{Hb}$ variants, the samples were kept at $-80^{\circ} \mathrm{C}(14,15)$ and analyzed within 1 month. Whole blood samples were obtained from the Clinical Laboratory of Guangdong Provincial Hospital of Chinese Medicine. Umbilical cord blood was collected by clinicians at the Department of Obstetrics and Gynecology of the Third Affiliated Hospital, Guangzhou Medical University, from the umbilical cord vein attached to the placenta, which had been detached from a newborn. Whole blood samples $(\mathrm{N}=151)$ were collected according to $\mathrm{HbA}_{1 \mathrm{c}}$ concentrations (3.0-15.0\%; 9-140 mmol/ mol) on a Premier Hb9210 instrument, with $\mathrm{HbF}<$ $1 \%$, normal $\mathrm{HbA}_{2}$ (2.5-3.5\%), and without $\mathrm{Hb}$ vari- 
ants on the Hb phenotype analysis by Bio-Rad Variant II (Bio-Rad, Japan) system using the beta thalassemia program. The $\mathrm{Hb}$ variants $\mathrm{HbA} / \mathrm{E}(\mathrm{N}=$ 6) (a substitution of lysine for glutamic acid at position 26 of the $\beta$ chain) were collected from routine laboratory testing samples for thalassemia and confirmed by DNA sequencing of $\mathrm{Hb}$ a and $\beta$-chain gene $\left(\mathrm{HBA}_{1}, \mathrm{HBA}_{2}\right.$ and $\left.\mathrm{HBB}\right)$ at the Beijing Genomics Institute (BGI, Shenzhen, China).

This study was approved by the Research and Ethics committee of our institution, and all participants signed their consents prior to the study.

\section{Precision}

The precision was evaluated in accordance with the EP15-A2 (16) protocol of the Clinical and Laboratory Standards Institute (CLSI). Two whole blood samples at levels of 5.0\% (31 $\mathrm{mmol} / \mathrm{mol})$ and $8.5 \%$ (69 $\mathrm{mmol} / \mathrm{mol}$ ) by Premier Hb9210 were divided into five aliquots per level and frozen at $-80^{\circ} \mathrm{C}$. One aliquot of each level was thawed daily, and the $\mathrm{HbA}_{1 c}$ value was analyzed three times per day during a period of five consecutive workdays ( $\mathrm{N}=$ 15 per level). Precision was evaluated as the coefficient of variation (CV), which is calculated from the data series mean and standard deviation. The formulas used to calculate CV were as follows:

$$
\begin{gathered}
S_{\text {within }}=\sqrt{\frac{\sum_{d=1}^{D} \sum_{i=1}^{n}\left(X_{d i}-\bar{X}_{d}\right)^{2}}{D(n-1)}} \\
S_{\text {total }}=\sqrt{\frac{n-1}{n} \times S_{\text {within }}^{2}+B} \\
B=\frac{\sum_{d=1}^{D}\left(\overline{X_{d}}-\overline{\bar{X}}\right)}{D-1}
\end{gathered}
$$

$$
\% \text { CVtotal }=\text { Stotal } / \overline{\bar{X}} \times 100 \%
$$

where $D$ is the total number of days (five), $n$ is the total number of replicates per day (three), $\mathrm{X}_{\mathrm{di}}$ is the result of replicate i for day $\mathrm{d}, \overline{X_{d}}$ is the average of all results for day $\mathrm{d}$, and $\overline{\bar{X}}$ is the average of all results.

Acceptable CV is recommended to be less than 3\% for SI units and 2\% for NGSP units (17-19).

\section{Linearity}

A test for linearity was carried out in accordance with the CLSI protocol EP6-A 8 (20). Linearity was investigated by preparing six different ratios of samples (5:0, 4:1, 3:2, 2:3, 1:4, and 0:5) from two samples with $\mathrm{HbA} 1 \mathrm{c}$ results of $4.2 \%(22 \mathrm{mmol} / \mathrm{mol})$ and $14.9 \%$ (139 mmol/mol) by Premier $\mathrm{Hb} 9210$ containing the same total $\mathrm{Hb}$ concentration (129 $\mathrm{g} / \mathrm{L}$ ). Each sample was assayed in duplicate, and the means were used to examine the linearity. The theoretical $\mathrm{HbA}_{1 \mathrm{c}}$ values (calculated from the ratios of the mixed packed-cells with high and low $\mathrm{HbA}_{1 \mathrm{c}}$ values) and the measured values were compared. Polynomial regression analysis was performed for first-, second-, and third-order polynomials.

\section{Accuracy}

Four samples used in the method comparison were validated by the Shanghai IFCC Reference Laboratory using the IFCC HPLC/CE reference method (21). The measurements of $\mathrm{HbA}_{1 c}$ were made in triplicate. The relative bias was calculated by each of the four system values against the IFCC reference method value for each sample. The proficiency testing acceptance limit $\pm 6 \%$ of College of American Pathologists (CAP) was set as the accuracy limit (relative bias was calculated by NGSP units) (7).

\section{Method comparison}

The correlation between systems was assessed by analyzing 93 samples representing a range of $\mathrm{HbA}_{1 \mathrm{c}}$ values $4.0-13.0 \%$ (20-119 $\mathrm{mmol} / \mathrm{mol}$ ) by Premier Hb9210. The boronate affinity HPLC method with the Premier Hb9210 instrument was used as the comparative method. 


\section{Analytical interferences}

Bilirubin, triglycerides/cholesterol, $L A_{1 c^{\prime}}$ vitamin $C$, and aspirin

Interferences of bilirubin, triglycerides/cholesterol, $\mathrm{LA}_{1 c^{\prime}}$ vitamin $\mathrm{C}$, and aspirin were evaluated in two native samples with $\mathrm{HbA}_{1 \mathrm{c}}$ results of $5.3 \%$ (34 $\mathrm{mmol} / \mathrm{mol}$ ) and $7.6 \%(60 \mathrm{mmol} / \mathrm{mol})$ by Premier $\mathrm{Hb} 9210$. Hyperbilirubinemic or triglycerides/cholesterol-rich plasma and drugs (glucose, vitamin C, and aspirin) were prepared: bilirubin $(<10 \mu \mathrm{mol} / \mathrm{L}$ and $445.50 \mu \mathrm{mol} / \mathrm{L}$; measured by Roche Modular $\mathrm{P}$ Chemistry Analyzer (Modular P), Roche Diagnostics, Germany), triglyceride (1.48, 10.21, and 19.10 $\mathrm{mmol} / \mathrm{L}$; measured by Roche Modular P), cholesterol $(4.63,10.29$, and $10.90 \mathrm{mmol} / \mathrm{L}$; measured by Roche Modular P), glucose $(277.78 \mathrm{mmol} / \mathrm{L}$; China Otsuka Pharmaceutical, Tianjin, China), vitamin C (ascorbic acid; $250 \mathrm{mg} / \mathrm{mL}$; CSPC Ouyi Pharmaceutical, Shijianzhuang, China), and aspirin (100 mg; Bayer Healthcare, Milano, Italy). Then, various dilutions were prepared by mixing the original pool with plasma or isotonic saline solution $(0.9 \%$, Jiangxi pharmaceutical, Ganzhou, China).

Interferences of bilirubin and triglycerides/cholesterol were assessed by mixing washed red blood cells with various dilutions of hyperbilirubinemic or triglycerides/cholesterol-rich plasma to achieve final concentrations of 89.10, 178.20, 267.30, 356.40, and $445.50 \mu \mathrm{mol} / \mathrm{L}$ bilirubin; 2.04, 4.08, 6.12, 8.16, and $10.21 \mathrm{mmol} / \mathrm{L}$ triglycerides; $2.06,4.12,6.18$, 8.23, and $10.29 \mathrm{mmol} / \mathrm{L}$ cholesterol; and 3.82 / 2.18, 7.64 / 4.36, 11.46 / 6.54, 15.28 / 8.72, and 19.10 / $10.90 \mathrm{mmol} / \mathrm{L}$ triglycerides/cholesterol.

Interference of $\mathrm{LA}_{1 c}$ was examined by incubating samples with various dilutions of glucose solutions $(5.65,27.78,55.56,138.89$, and $277.78 \mathrm{mmol} / \mathrm{L})$ at 37 ${ }^{\circ} \mathrm{C}$ for $3 \mathrm{~h}$, and the samples were mixed every 30 min prior to the assay (22). The amount of $L A_{1 c}$ formed was estimated using a Tosoh G8 analyzer $\left(\mathrm{LA}_{1 \mathrm{c}}\right.$ can be separated from $\mathrm{HbA}_{1 \mathrm{c}}$ and others, and the percentage value is the percentage of total $\mathrm{Hb}$ as reported).

Interference of vitamin C or aspirin was performed by mixing blood samples spiked with various dilutions of vitamin C or aspirin solution (final concen- trations: $25,50,100,150,200$, and $250 \mathrm{mg} / \mathrm{mL}$ vitamin C; and 6.66, 13.32, 19.98, 26.64, and $33.30 \mathrm{mg} /$ $\mathrm{mL}$ aspirin).

The measurements of $\mathrm{HbA}_{1 c}$ were made in triplicate, and the relative bias of each specimen was calculated from the observed value against the baseline value.

$\mathrm{HbF}$

Interference with $\mathrm{HbF}$ was evaluated by mixing 40 native samples representing a range of $\mathrm{HbA}_{1 c}$ values (4-13\%; 20-119 $\mathrm{mmol} / \mathrm{mol}$ ) with umbilical cord blood in order to obtain 6 groups with final $\mathrm{HbF}$ concentrations of $5-10 \%(\mathrm{~N}=5), 10-15 \%(\mathrm{~N}=5)$, $15-20 \%(\mathrm{~N}=7), 20-25 \%(\mathrm{~N}=10), 25-30 \%(\mathrm{~N}=5)$, and $30-40 \%(\mathrm{~N}=8)$. The $\mathrm{HbF}$ concentration was analyzed by the Tosoh $\mathrm{G} 8$ instrument as the $\mathrm{HbF}$ percentage $\left(\mathrm{HbF}\right.$ can be separated from $\mathrm{HbA}_{1 \mathrm{c}}$ and others, and the percentage value is the percentage of total $\mathrm{Hb}$ as reported).

The measurements of $\mathrm{HbA}_{1 c}$ were made in triplicate. The relative bias of each specimen was calculated from the observed value and the baseline value (NGSP units).

\section{Hb variant}

Interference with a $\mathrm{Hb}$ variant was tested in several samples containing the most frequent $\mathrm{Hb}$ variant $\mathrm{HbA} / \mathrm{E}(\mathrm{N}=6)$. The boronate affinity HPLC method with the Premier Hb9210 instrument was used as the comparative method as it is not expected to be influenced by the presence of $\mathrm{Hb}$ variants (23). For each test method, the results were compared to those obtained using the comparison method.

\section{Statistical analysis}

Data analysis was performed using MedCalc version 14.8.1 (MedCalc Software, Ostend, Belgium). The method comparisons were performed by Passing-Bablok regression, and the differences between any two methods were presented in a Bland-Altman plot. For method comparison and analytical interferences, relative bias $> \pm 7 \%$ (calculated by NGSP units) was considered clinically significant (NGSP criterion) (7). 


\section{Results}

\section{Precision}

The within-run $\mathrm{CV}$ s at low and high $\mathrm{HbA}_{1 \mathrm{c}}$ concentrations on all four systems were less than $2.0 \%$ and $1.2 \%$ (with IFCC units), or $1.3 \%$ and $1.0 \%$ (with NGSP units), respectively (Table 1). The total CVs at the low and high $\mathrm{HbA}_{1 \mathrm{c}}$ levels were less than $2.0 \%$ and $1.7 \%$ (with IFCC units), and $1.4 \%$ and $1.5 \%$ (with NGSP units), respectively (Table 1).

\section{Linearity}

The linear regression analysis for each of the four analyzers showed a line with a good correlation coefficient $\left(R^{2}>0.99\right)$ over the entire range tested (Table 1).

\section{Accuracy}

The relative bias against the IFCC targets was less than $\pm 6 \%$ for all four systems tested (NGSP units), indicating a good accuracy of these methods (Table 2).

\section{Method comparison}

The correlation between the Capillarys 2FP and Premier Hb9210 analyzers, expressed in NGSP units, is described with the Passing-Bablok regression fit: $Y=1.07$ (95\% confidence interval $(\mathrm{Cl})$ : 1.03 to 1.10$) \mathrm{X}-0.31$ (95\% Cl: -0.51 to -0.08$)$, without significant deviation from linearity $(P=0.13)$ (Figure $1 \mathrm{~A})$. The Bland-Altman plot showed a mean absolute difference of $0.13 \% \mathrm{HbA}_{1 \mathrm{c}}$ (Figure 1B). All samples had less than $7 \%$ relative difference.

The correlation between the Tosoh G8 and Premier $\mathrm{Hb} 9210$ analyzers, expressed in NGSP units, is described with the Passing-Bablok regression fit: $Y$ $=1.02$ (95\% Cl: 1.00 to 1.05$) \mathrm{X}-0.01$ (95\% Cl: -0.23 to 0.10$)$, without significant deviation from linearity $(P=0.46)$ (Figure $1 C)$. The Bland-Altman plot showed a mean absolute difference of $0.13 \% \mathrm{HbA}_{1 \mathrm{c}}$ (Figure 1D). All samples had less than $7 \%$ relative difference.

The correlation between the Roche c501 and Premier Hb9210 analyzers, expressed in NGSP units, is described with the Passing-Bablok regression fit: $Y$ $=0.96$ (95\% Cl: 0.93 to 1.00$) X+0.23(95 \% \mathrm{Cl}: 0.00$
TABLE 1. Precision and linearity of $\mathrm{HbA}_{1 c}$ values analyzed by the four analyzers

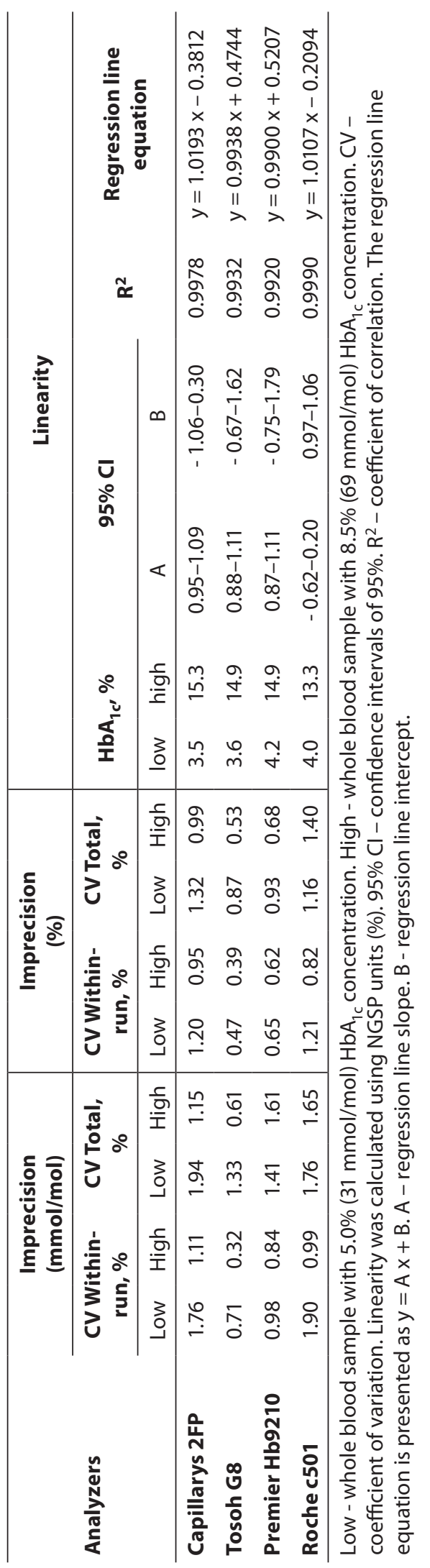

Biochemia Medica 2016;26(3):353-64 
TABLE 2. Accuracy of $\mathrm{HbA}_{1 \mathrm{c}}$ values analyzed by the four analyzers

\begin{tabular}{|c|c|c|c|c|c|c|c|c|c|}
\hline \multirow{2}{*}{$\begin{array}{l}\text { Sample } \\
\text { number }\end{array}$} & \multicolumn{5}{|c|}{ HbA1c, \% } & \multicolumn{4}{|c|}{ Relative bias, \% } \\
\hline & $\begin{array}{l}\text { Target } \\
\text { value }\end{array}$ & $\begin{array}{c}\text { Capillarys } \\
\text { 2FP }\end{array}$ & Tosoh G8 & $\begin{array}{l}\text { Premier } \\
\text { Hb9210 }\end{array}$ & $\begin{array}{l}\text { Roche } \\
\text { c501 }\end{array}$ & $\begin{array}{c}\text { Capillarys } \\
\text { 2FP }\end{array}$ & Tosoh G8 & $\begin{array}{l}\text { Premier } \\
\text { Hb9210 }\end{array}$ & Roche c501 \\
\hline 1 & 5.4 & 5.4 & 5.7 & 5.2 & 5.2 & 0.0 & 5.6 & -3.7 & -3.7 \\
\hline 2 & 6.1 & 6.4 & 6.2 & 6.0 & 6.2 & 4.9 & 1.6 & -1.6 & 1.6 \\
\hline 3 & 7.8 & 7.9 & 8.0 & 7.6 & 7.6 & 1.3 & 2.6 & -2.6 & -2.6 \\
\hline 4 & 10.4 & 10.7 & 10.5 & 10.3 & 10.1 & 2.9 & 1.0 & -1.0 & -2.9 \\
\hline
\end{tabular}

The CAP proficiency testing acceptance limit of $\pm 6 \%$ was set as the accuracy limit (relative bias was calculated by NGSP units).

to 0.45$)$, without significant deviation from linearity $(P=0.08)$ (Figure $1 \mathrm{E})$. The Bland-Altman plot showed a mean absolute difference of $-0.04 \%$ $\mathrm{HbA1c}$ (Figure 1F). All samples had less than $7 \%$ relative difference.

\section{Analytical interferences}

Assessment of interferences is shown in Table 3. No interference was observed with Capillarys 2FP, Premier Hb9210, and Tosoh G8 at the following interfering substance concentrations tested: 445.50 $\mu \mathrm{mol} / \mathrm{L}$ bilirubin, $10.21 \mathrm{mmol} / \mathrm{L}$ triglyceride, 10.29 $\mathrm{mmol} / \mathrm{L}$ cholesterol, or 19.10 / $11.90 \mathrm{mmol} / \mathrm{L}$ triglycerides/cholesterol. On Roche c501 analyzer, no analytical interference of bilirubin was noticed for concentrations reaching $445.50 \mu \mathrm{mol} / \mathrm{L}$; while, at concentrations of 15.28 / 8.72 and 19.10 / 11.90 $\mathrm{mmol} / \mathrm{L}$ triglycerides/cholesterol, a significant bias was observed (relative bias $> \pm 7 \%$ ).

A glucose concentration less than $277.78 \mathrm{mmol} / \mathrm{L}$ $\left(\mathrm{LA}_{1 \mathrm{c}}<10.9 \%\right)$ did not interfere with $\mathrm{HbA}_{1 c}$ quantification on any of the four analyzers. In addition, no significant bias was observed with the results analyzed by the Capillarys 2FP analyzer in the presence of vitamin C up to $250 \mathrm{mg} / \mathrm{mL}$. In contrast, using the Premier Hb9210 and Tosoh G8 analyzers, vitamin $C$ concentrations of more than 50 and $150 \mathrm{mg} / \mathrm{mL}$, respectively, interfered with the $\mathrm{HbA}_{1 \mathrm{c}}$ measurements.

Moreover, the $\mathrm{HbA}_{1 \mathrm{c}}$ value was falsely increased only with the Tosoh G8 analyzer at an aspirin concentration exceeding $26.64 \mathrm{mg} / \mathrm{mL}$ in the samples.

Compared with the native sample, on the Capillarys 2FP analyzer, significant biases were observed in samples with $10-15 \% \mathrm{HbF}$ (relative bias $> \pm 7 \%$ ). On the Premier Hb9210 analyzer, the results were not affected in the two groups of samples with 5 $-10 \%$ and $10-15 \% \mathrm{HbF}$ (relative bias < $47 \%$ ). On the Tosoh $\mathrm{G} 8$ analyzer, the $\mathrm{HbA}_{1 \mathrm{c}}$ results were obtained by a correction via excluding the $\mathrm{HbF}$ peak from the total integrated area, resulting in an insignificant interference in the samples with $\mathrm{HbF}<$ $30 \%$ (relative bias $< \pm 7 \%$ ). For all samples analyzed by the Roche $\mathrm{c} 501$ analyzer, the $\mathrm{HbA}_{1 \mathrm{c}}$ results were influenced by elevated $\mathrm{HbF}$ values $>5 \%$ (relative bias $> \pm 7 \%$ for all groups).

The Capillarys 2FP analyzer gave a perfect separation of the variant $\mathrm{HbE}$; on the Tosoh $\mathrm{G} 8$ analyzer, an extra peak was present between the $A_{1 c}$ and $A_{0}$ peaks (Figure 2). A rather good agreement was noticed between the Capillarys 2FP/Roche c501 and Premier Hb9210 analyzers (relative bias < $<7 \%$ ); meanwhile, a significant negative bias of $\mathrm{HbA}_{1 \mathrm{c}}$ values was observed systematically on the Tosoh G8 system in comparison with the Premier Hb9210 analyzer (relative bias $> \pm 7 \%$ ).

\section{Discussion}

The data presented here are comparative evaluations of the analytical performance of four commonly used systems: Capillarys 2FP, Tosoh G8, Premier Hb9210, and Roche c501 Tina-quant Gen2. Precision studies showed good performances, with CVs of the four $\mathrm{HbA}_{1 \mathrm{c}}$ assays well within the recommendations (below $3 \%$ for IFCC units and $2 \%$ for NGSP units) (17-19). The linearity was excellent over the clinical range of $\mathrm{HbA}_{1 \mathrm{c}}$ values. Accu- 
A

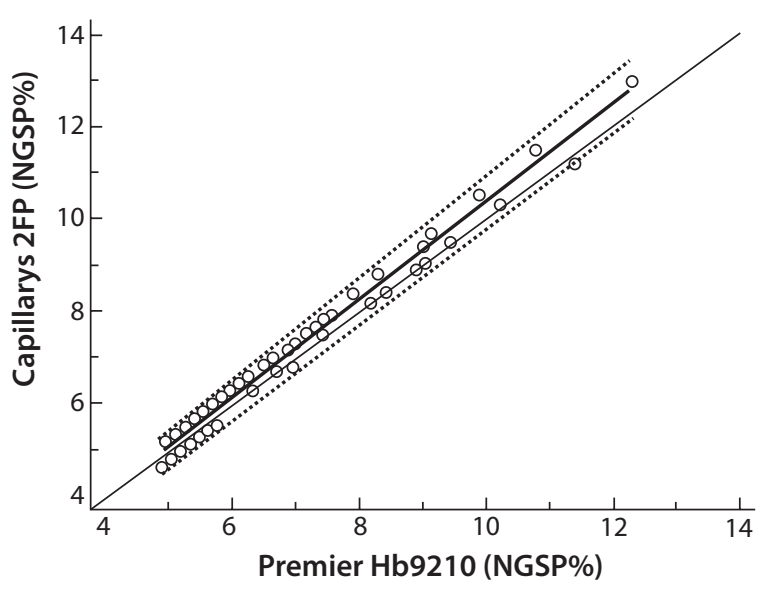

C

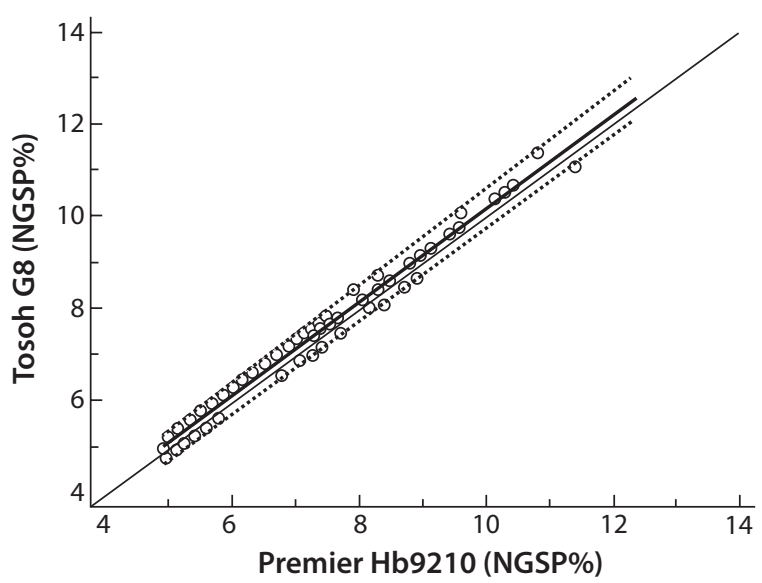

E

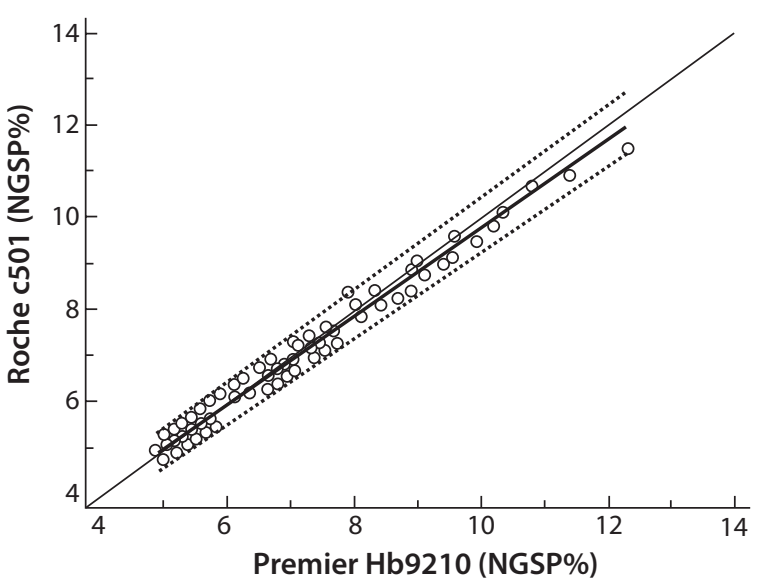

B

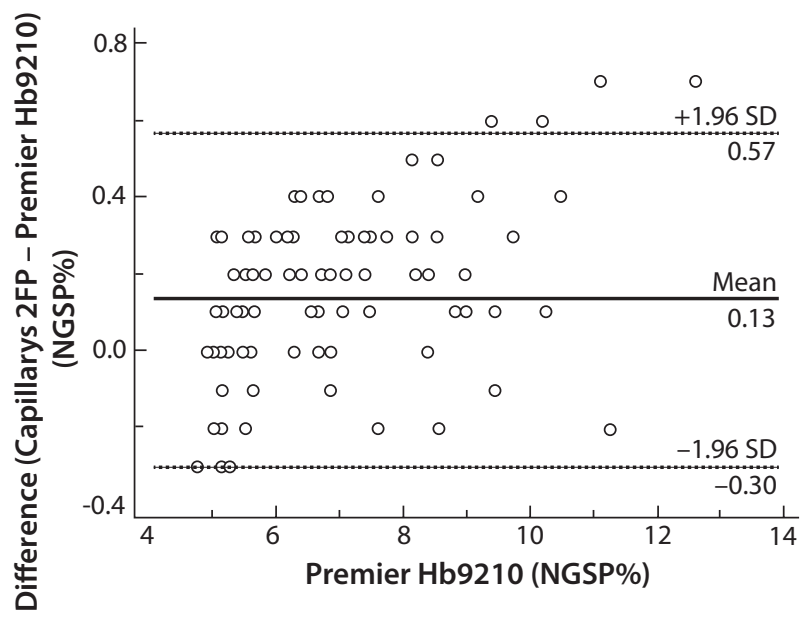

D

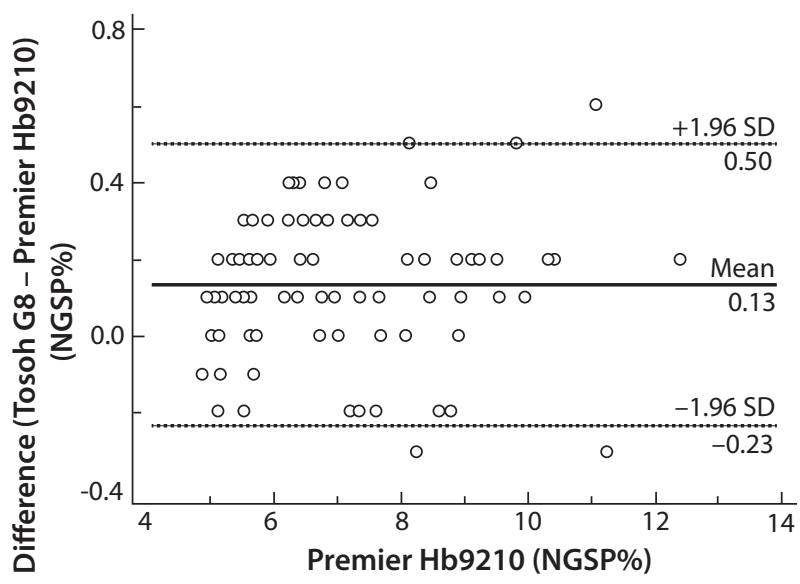

$\mathbf{F}$

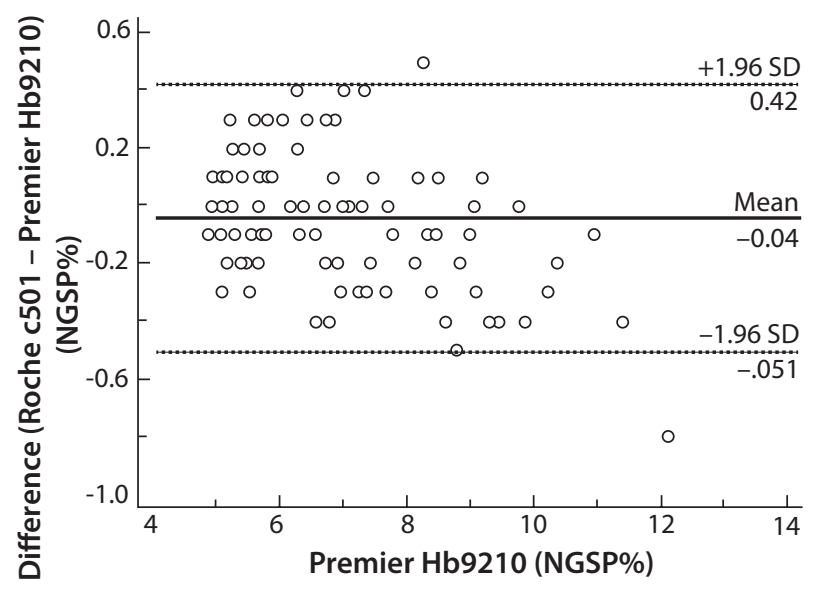

FigURE 1. Comparison of HbA1c values obtained with four analyzer using Passing and Bablok (PB) regression analysis and Bland-Altman (BA) plot. (A) Comparison of Capillarys 2FP and Premier Hb9210 by PB. (B) Comparison of Capillarys 2FP and Premier Hb9210 by BA. (C) Comparison of Tosoh G8 and Premier Hb9210 by PB. (D) Comparison of Tosoh G8 and Premier Hb9210 by BA. (E) Comparison of Roche c501 and Premier Hb9210 by PB. (F) Comparison of Roche c501 and Premier Hb9210 by BA. In the Passing-Bablok regression analyses the dotted lines show the $95 \%$ confidence interval $(\mathrm{Cl})$; the gray lines represent the identity line $(\mathrm{X}=\mathrm{Y})$. In the Bland-Altman plots the solid lines show the mean difference, while the dotted lines show the mean difference \pm 1.96 SD. 
TABLE 3. Sample interferences for common interferents

\begin{tabular}{|c|c|c|c|c|c|c|c|c|}
\hline \multirow{3}{*}{ Interferent } & \multicolumn{8}{|c|}{ Relative bias from native sample, $\%$} \\
\hline & \multicolumn{2}{|c|}{ Capillarys 2 FP } & \multicolumn{2}{|c|}{ TOSOH G8 } & \multicolumn{2}{|c|}{ Premier Hb9210 } & \multicolumn{2}{|c|}{ Roche c501 } \\
\hline & Low & High & Low & High & Low & High & Low & High \\
\hline \multicolumn{9}{|l|}{ TBIL, $\mu \mathrm{mol} / \mathrm{L}$} \\
\hline 89.1 & 3.64 & 0.00 & 1.89 & 0.00 & 1.89 & -2.63 & 1.13 & 0.26 \\
\hline 178.2 & -1.82 & 0.00 & 0.00 & 1.28 & 1.89 & -1.32 & 1.89 & -0.79 \\
\hline 267.3 & -3.64 & 3.85 & 0.00 & 0.00 & 1.89 & 0.00 & 1.32 & -1.18 \\
\hline 356.4 & -1.82 & 1.28 & 1.89 & 0.00 & 1.89 & -1.32 & -0.19 & -2.76 \\
\hline 445.5 & -1.82 & 1.28 & 1.89 & 0.00 & 1.89 & 1.32 & -0.38 & -3.55 \\
\hline \multicolumn{9}{|l|}{ TG, mmol/L } \\
\hline 2.04 & -3.64 & 1.28 & 1.89 & 0.00 & 0.00 & -1.32 & -1.13 & 3.42 \\
\hline 4.08 & -3.64 & 2.56 & 0.00 & 0.00 & 0.00 & -2.63 & -2.45 & 1.32 \\
\hline 6.12 & -3.64 & 1.28 & 0.00 & -1.28 & -1.89 & -2.63 & -1.51 & -1.45 \\
\hline 8.16 & -3.64 & -1.28 & 0.00 & -1.28 & -1.89 & -3.95 & -3.77 & 1.18 \\
\hline 10.21 & -1.82 & -1.28 & 0.00 & 0.00 & 1.89 & -1.32 & -0.38 & -1.71 \\
\hline \multicolumn{9}{|c|}{ CHOL, $\mathrm{mmol} / \mathrm{L}$} \\
\hline 2.06 & -3.64 & -2.56 & 0.00 & 0.00 & 1.89 & -1.32 & -2.83 & -3.68 \\
\hline 4.12 & -3.64 & -3.85 & 1.89 & 0.00 & 0.00 & -1.32 & -2.83 & -3.16 \\
\hline 6.18 & -3.64 & -1.28 & 0.00 & -1.28 & 1.89 & -1.32 & -4.53 & -3.16 \\
\hline 8.23 & -3.64 & -3.85 & 0.00 & -1.28 & 1.89 & -1.32 & -4.15 & -1.58 \\
\hline 10.29 & 0.00 & -1.28 & -1.89 & -1.28 & 0.00 & -1.32 & -3.21 & -2.50 \\
\hline \multicolumn{9}{|c|}{$\mathrm{TG} / \mathrm{CHOL}, \mathrm{mmol} / \mathrm{L}$} \\
\hline $3.82 / 2.18$ & -3.64 & -1.28 & 1.89 & 0.00 & 3.77 & -1.32 & -1.70 & -3.55 \\
\hline $7.64 / 4.36$ & 0.00 & -1.28 & 0.00 & 1.28 & 1.89 & -2.63 & -2.83 & -3.42 \\
\hline $11.46 / 6.54$ & 0.00 & 0.00 & 1.89 & -1.28 & 1.89 & -1.32 & -4.15 & -3.42 \\
\hline $15.28 / 8.72$ & 0.00 & 2.56 & 1.89 & 0.00 & 3.77 & -2.63 & -7.74 & -5.13 \\
\hline $19.10 / 11.90$ & 0.00 & 1.28 & 1.89 & 0.00 & 3.77 & -2.63 & -8.79 & -5.26 \\
\hline \multicolumn{9}{|l|}{ Vit C, mg/mL } \\
\hline 25 & / & / & / & / & 3.8 & 4.8 & / & / \\
\hline 50 & 1.92 & 0.00 & 3.70 & 1.23 & 20.75 & 10.53 & 4.53 & -1.45 \\
\hline 100 & 0.00 & -1.27 & 5.56 & 1.23 & 50.94 & 25.00 & 6.42 & 6.32 \\
\hline 150 & -5.77 & 1.27 & 14.81 & 4.94 & 56.60 & 32.89 & 10.00 & 7.37 \\
\hline 200 & 1.92 & -2.53 & 24.07 & 7.41 & 52.83 & 34.21 & 6.04 & 5.92 \\
\hline 250 & 0.00 & 0.00 & 22.22 & 8.64 & 50.94 & 32.89 & 4.72 & 3.42 \\
\hline \multicolumn{9}{|c|}{ Aspirin (mg/mL) } \\
\hline 6.66 & -1.82 & -2.56 & 3.70 & 0.00 & 1.89 & -1.32 & 3.58 & -0.53 \\
\hline 13.32 & -1.82 & -3.85 & 5.56 & 1.23 & 3.77 & -1.32 & 2.08 & 1.18 \\
\hline 19.98 & -3.64 & -5.13 & 5.56 & 2.47 & 1.89 & -1.32 & 2.08 & -1.18 \\
\hline 26.64 & -3.64 & 0.00 & 9.26 & 2.47 & 1.89 & 0.00 & -0.19 & 0.13 \\
\hline 33.33 & -3.64 & -1.28 & 11.11 & 3.70 & 0.00 & -2.63 & 2.45 & 1.45 \\
\hline \multicolumn{9}{|l|}{ Glu (mmol/L) } \\
\hline 5.56 & 1.82 & 1.16 & 0.00 & 0.00 & 0.00 & 1.19 & 2.82 & 4.81 \\
\hline 27.78 & -1.82 & 1.16 & 0.00 & 0.00 & 0.00 & 0.00 & -0.56 & 4.44 \\
\hline 55.56 & -3.64 & 0.00 & 0.00 & -3.49 & 1.82 & -2.38 & 0.00 & 0.99 \\
\hline 138.89 & -3.64 & -1.16 & 0.00 & -3.49 & 1.82 & -2.38 & 1.13 & 0.74 \\
\hline 277.78 & -3.64 & 0.00 & 0.00 & -4.65 & 5.45 & -1.19 & 2.07 & 0.00 \\
\hline
\end{tabular}

Low - whole blood sample with $\mathrm{HbA}_{1 \mathrm{c}}$ concentration of $5.3 \%$ measured by Premier $\mathrm{Hb} 9210$. High - whole blood sample with $\mathrm{HbA}_{1 \mathrm{c}}$ concentration of $7.6 \%$ measured by Premier Hb9210. TBIL - total bilirubin. TG - triglycerides. CHOL - cholesterol. Vit C - vitamin C. Glu - glucose. "I" - not performed. The bold results show relative bias $> \pm 7 \%$ (calculated by NGSP units). Relative bias $> \pm 7 \%$ was considered clinically significant (NGSP criterion). 

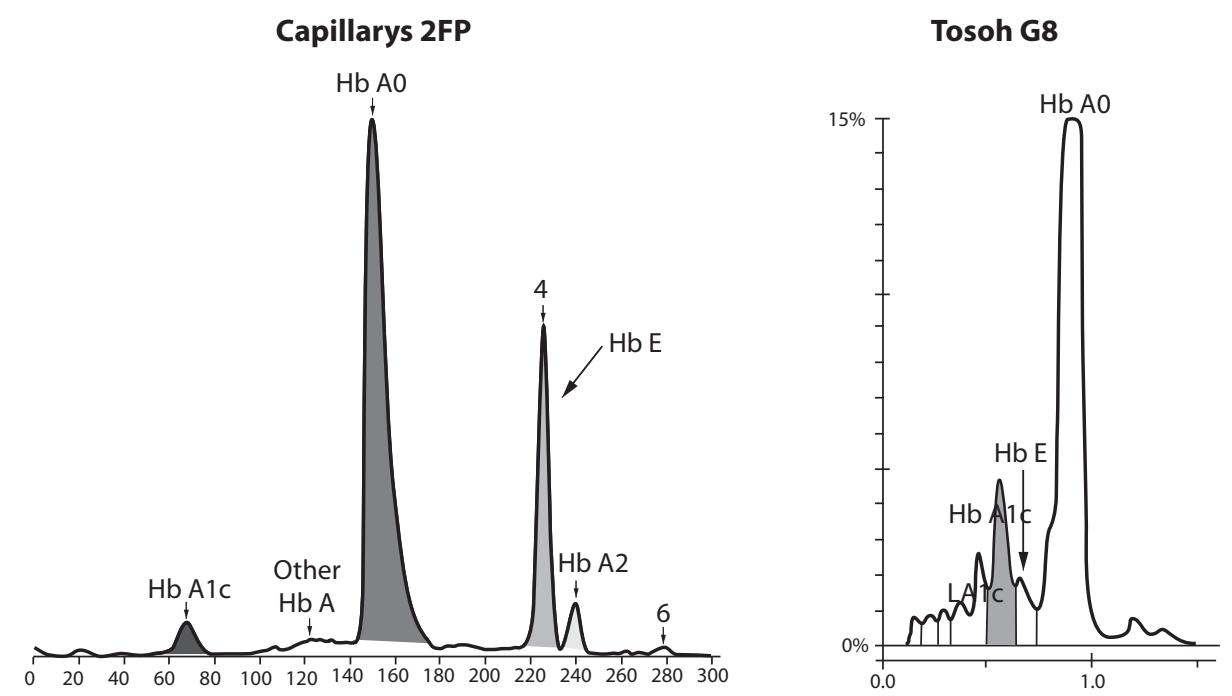

FIGURE 2. Detection of HbE with the Capillarys 2FP and Tosoh G8 analyzers. The arrow indicates the presence of the variant (HbE).

racy verification demonstrated a great consistency among the four systems tested in comparison with the IFCC values. The high analytical performances in terms of precision, linearity, and accuracy of all four systems were in accordance with previous studies $(15,24-27)$ and manufacturer claims.

In the $\mathrm{HbA}_{1 c}$ comparison study, Passing-Bablock regression analysis highlighted a good correlation between any two methods. Moreover, the BlandAltman plot showed that the $\mathrm{HbA}_{1 c}$ values between any two of the four systems were in good agreement.

The measurement of $\mathrm{HbA}_{1 \mathrm{c}}$ by the Capillarys 2FP, Tosoh G8, and Premier Hb9210 analyzers was not subjected to common interferences such as bilirubin and triglycerides/cholesterol, and these findings confirmed the results presented previously $(15,24,25,28)$. However, very high levels of triglycerides/cholesterol led to a falsely low $\mathrm{HbA}_{1 \mathrm{c}}$ value in the immunoassay using the Roche c501 system. Furthermore, it seems that samples with a low $\mathrm{HbA}_{1 \mathrm{c}}$ value are more susceptible to interference. According to the manufacturer's claim, no interference is observed with lipemic samples containing triglycerides concentrations less than 15.52 $\mathrm{mmol} / \mathrm{L}$.

$\mathrm{LA}_{1 \mathrm{c}}$ is an intermediate molecule, and its concentration is associated with blood glucose concentra-

TABLE 4. $\mathrm{HbA}_{1 \mathrm{C}}$ values for $\mathrm{HbE}$ on the Capillarys $2 \mathrm{FP}$, Tosoh G8, Premier Hb9210, and Roche c501 systems

\begin{tabular}{|c|c|c|c|c|c|c|c|}
\hline \multirow{2}{*}{ Sample } & \multicolumn{4}{|c|}{$\mathrm{HbA}_{1 c^{\prime}} \%$} & \multicolumn{3}{|c|}{ Relative bias from Premier Hb9210, \% } \\
\hline & Premier Hb9210 & Capillarys 2FP & Tosoh G8 & Roche c501 & Capillarys 2FP & Tosoh G8 & Roche $c 501$ \\
\hline 1 & 5.5 & 5.6 & 4.2 & 5.4 & 1.8 & -23.6 & -1.8 \\
\hline 2 & 5.0 & 4.8 & 4.2 & 5.0 & -4.0 & -16.0 & 0.0 \\
\hline 3 & 5.3 & 5.3 & 4.7 & 5.6 & 0.0 & -11.3 & 5.6 \\
\hline 4 & 5.1 & 5.2 & 4.1 & 5.2 & 2.0 & -19.6 & 2.0 \\
\hline 5 & 5.6 & 5.9 & 4.6 & 5.7 & 5.4 & -18.0 & 1.8 \\
\hline 6 & 5.6 & 5.3 & 4.6 & 5.4 & -5.4 & -18.0 & -3.6 \\
\hline
\end{tabular}

The boronate affinity HPLC method with the Premier Hb9210 instrument was used as the comparative method. The bold results show the relative bias $> \pm 7 \%$ (calculated by NGSP units). Relative bias $> \pm 7 \%$ was considered clinically significant (NGSP criterion). 
tions. The isoelectric points of $\mathrm{LA}_{1 \mathrm{c}}$ and its stable counterpart are similar, which may lead to little or no separation between them by some methods that rely on molecular charge for separation. In this study, no effect was reported on the quantification of $\mathrm{HbA}_{1 \mathrm{c}}$ by the two methods based on the principle of molecular charge. The current study showed that treatment with glucose up to 277.78 $\mathrm{mmol} / \mathrm{L}$ in vitro, much higher than the concentration reported previously $(15,24,29)$ and the manufacturer's claims, did not interfere with the $\mathrm{HbA}_{1 \mathrm{c}}$ measurement, suggesting that the blood $L_{1 c}$ contents may not affect the quantification of $\mathrm{HbA}_{1 \mathrm{c}}$ by the four tested methods.

In our study, for the concentration of vitamin C or aspirin at a dose higher than clinical relevance, it is presumed that the concentration of vitamin $C$ or aspirin in patient samples does not affect $\mathrm{HbA}_{1 \mathrm{c}}$ results tested by the four analyzers in clinical practice. Chronic ingestion of aspirin or vitamin $C$ in high doses may promote acetylation of $\mathrm{HbA}_{1 \mathrm{c}}$ chains or inhibit $\mathrm{Hb}$ glycation, thereby affecting $\mathrm{HbA}_{1 \mathrm{c}}$ results (13,30-33). Thus, the effects of aspirin and vitamin $\mathrm{C}$ on $\mathrm{HbA}_{1 c}$ assays are uncertain, and they may be of a biological nature rather than an analytical interference, although this needs to be investigated in a future study.

With the Capillarys 2FP instrument, at an increased proportion of $\mathrm{HbF}$ greater than $10 \%$, which is in excess of that reported by Jaisson et al. (24), the separation of $\mathrm{HbF}$ and $\mathrm{HbA}_{0}$ could not be accomplished, resulting in a false result. As the $\mathrm{HbF}$ amount was excluded from the total integrated amount through using the Tosoh G8 instrument software, it may not interfere with the $\mathrm{HbA}_{1 \mathrm{c}}$ measurement at a concentration $<30 \%$, in agreement with a previous evaluation and NGSP reports $(7,8)$. Elevated $\mathrm{HbF}>15 \%$, in agreement with boronate affinity methods reported by the NGSP, can affect the $\mathrm{HbA}_{1 \mathrm{c}}$ results using the Premier Hb9210 system, which might be due to a lower glycation rate of $\mathrm{HbF}$ compared with that of $\mathrm{HbA}$ (7). The $\mathrm{HbA}_{1 \mathrm{c}}$ concentrations can be misestimated with the Roche $c 501$ instrument at a higher $\mathrm{HbF}$ level ( > $5 \%$ in our study). However, there are no manufacturer claims of $\mathrm{HbF}$ interference. According to the
NGSP, HbF levels > 10-15\% can interfere with the Tina-quant Gen2 assay (7). Elevated HbF levels can occur under some pathological conditions such as beta-thalassemia, delta/beta-thalassemia, or a hereditary persistence of $\mathrm{HbF}(\mathrm{HPFH})$. The four instruments would lead to inaccurate results using different concentrations of $\mathrm{HbF}$; therefore, it is important for laboratories to consider this fact in areas of a high prevalence of thalassemia or HPFH.

Over 1000 different $\mathrm{Hb}$ variants have been discovered. Quantification of $\mathrm{HbA}_{1 c}$ in the presence of an $\mathrm{Hb}$ variant is an analytical challenge in the clinical laboratory. The most common $\mathrm{Hb}$ variants worldwide in descending order of prevalence are $\mathrm{HbS}$, $\mathrm{HbE}, \mathrm{HbC}$, and $\mathrm{HbD}$. As the second most prevalent hemoglobinopathy worldwide, $\mathrm{HbE}$ is mostly found in the Far East and Southeast Asia; thus, it has been included in the present study (11). A good agreement of $\mathrm{HbA}_{1 \mathrm{c}}$ concentrations was observed between the Capillarys 2FP, Roche c501, and Premier Hb9210 analyzers; therefore, it was concluded that the $\mathrm{HbA1c}$ measurements on these three systems were not affected by the presence of the $\mathrm{HbE}$ variant, confirming the results reported previously $(9,10,15,23-25,28)$. However, on the Tosoh $\mathrm{G} 8$ instrument, the presence of $\mathrm{HbE}$ induces an extra peak on the chromatogram, which is not reportable as shown previously $(10,23)$.

In summary, the four $\mathrm{HbA}_{1 c}$ methods commonly used with commercial analyzers showed a good comparability and reliability, although some interference may impede the results.

\section{Acknowledgments}

This research was supported by grants from the National Key Technologies R\&D Program of China (2012BAI37B01), the National Special R\&D Program of Major New Drugs of China (2012ZX09303009003), the National Natural Science Foundation of China (81572088), the Natural Science Foundation of Guangdong Province (2015A030313340), and the Foundation of Guangdong Provincial Hospital of Chinese Medicine (2014KT1593).

\section{Potential conflict of interest}

None declared. 


\section{References}

1. Peterson KP, Pavlovich JG, Goldstein D, Little R, England J, Peterson CM. What is hemoglobin A1c? An analysis of glycated hemoglobins by electrospray ionization mass spectrometry. Clin Chem 1998;44:1951-8.

2. The Diabetes Control and Complications Trial Research Group. The effect of intensive treatment of diabetes on the development and progression of long-term complications in insulin-dependent diabetes mellitus. $N$ Engl J Med 1993;329:977-86. http://dx.doi.org/10.1056/ NEJM199309303291401.

3. UK Prospective Diabetes Study (UKPDS) Group. Intensive blood-glucose control with sulphonylureas or insulin compared with conventional treatment and risk of complications in patients with type 2 diabetes (UKPDS 33). Lancet 1998;352:837- 53. http://dx.doi.org/10.1016/S01406736(98)07019-6.

4. Sacks DB, Arnold M, Bakris GL, Bruns DE, Horvath AR, Kirkman MS, et al. National Academy of Clinical Biochemistry; Evidence-Based Laboratory Medicine Committee of the American Association for Clinical Chemistry. Guidelines and recommendations for laboratory analysis in the diagnosis and management of diabetes mellitus. Diabetes Care 2011; 34:e61-99. http://dx.doi.org/10.2337/dc11-9998.

5. Gillett MJ. International Expert Committee report on the role of the A1c assay in the diagnosis of diabetes. Diabetes Care 2009;32:1327-34. http://dx.doi.org/10.2337/dc099033.

6. Weykamp C, John WG, Mosca A. A review of the challenge in measuring hemoglobin A1c. J Diabetes Sci Technol 2009; 3:439-45. http://dx.doi.org/10.1177/193229680900300306.

7. National Glycohemoglobin Standardization Program. Available at: http://www.ngsp.org. Accessed May 10th 2016.

8. Little RR, Rohlfing CL, Hanson SE, Schmidt RL, Lin CN, Madsen $R W$, et al. The effect of increased fetal hemoglobin on 7 common Hb A1c assay methods. Clin Chem 2012; 58:945-7. http://dx.doi.org/10.1373/clinchem.2012.181933.

9. Jaisson S, Leroy $N$, Desroches $C$, Tonye-Libyh $M$, Guillard $E$, Gillery $P$. Interference of the most frequent haemoglobin variants on quantification of $\mathrm{HbA} 1 \mathrm{c}$ :comparison between the LC-MS (IFCC reference method) and three routinely used methods. Diabetes Metab 2013;39:363-9. http://dx.doi. org/10.1016/j.diabet.2013.01.004.

10. Little RR, Rohlfing CL, Hanson S, Connolly S, Higgins $T$, Weykamp CW, et al. Effects of Hemoglobin $(\mathrm{Hb}) \mathrm{E}$ and $\mathrm{HbD}$ Traits on Measurements of Glycated $\mathrm{Hb}$ (HbA1c) by 23 Methods. Clin Chem 2008; 54:1277-82. http://dx.doi. org/10.1373/clinchem.2008.103580

11. Tanphaichitr VS, Mahasandana C, Suvatte V, Yodthong $S$, Pung-amritt $P$, Seeloem J. Prevalence of hemoglobin E. Southeast Asian J Trop Med Public Health 1995;26:S271-4.

12. Little RR, Roberts WL. A review of variant hemoglobins interfering with hemoglobin A1C measurement. J Diabetes Sci Technol 2009; 3:446-51. http://dx.doi. org/10.1177/193229680900300307.
13. Camargo JL, Stifft J, Gross JL. The effect of aspirin and vitamins C and E on HbA1c assays. Clin Chim Acta 2006;372:2069. $h t t p: / / d x$. doi.org/10.1016/j.cca.2006.03.031.

14. Simon $M$, Hoover JD. Effect of sample instability on glycohemoglobin (HbA1) measured by cation-exchange chromatography. Clin Chem 1982;28:195-8.

15. John WG, Little R, Sacks DB, Weykamp C, Lenters-Westra $E$, Hornsby $T$, et al. Multicentre evaluation of the Premier Hb9210 HbA1c analyser. Clin Chem Lab Med 2015;53:31927. http://dx.doi.org/10.1515/cclm-2014-0589.

16. Clinical and Laboratory Standards Institute. User verification of performance for precision and trueness; approved guideline-second edition. Ep15-a2. Wayne, PA, USA, 2005.

17. Weykamp CW, Mosca A, Gillery P, Panteghini M. The analytical goals for hemoglobin A(1c) measurement in IFCC units and National Glycohemoglobin Standardization Program Units are different. Clin Chem 2011;57:1204-6. http://dx.doi. org/10.1373/clinchem.2011.162719.

18. Goodall I, Colman PG, Schneider HG, McLean M, Barker G. Desirable performance standards for $H b A(1 c)$ analysisprecision, accuracy and standardisation: consensus statement of the Australasian Association of Clinical Biochemists $(A A C B)$, the Australian Diabetes Society $(A D S)$, the Royal College of Pathologists of Australasia (RCPA), Endocrine Society of Australia (ESA), and the Australian Diabetes Educators Association (ADEA). Clin Chem Lab Med 2007;45:108397. $h$ ttp://dx.doi.org/10.1515/CCLM.2007.158.

19. Sacks DB, Arnold M, Bakris GL, Bruns DE, Horvath AR, Kirkman MS, et al. Guidelines and recommendations for laboratory analysis in the diagnosis and management of diabetes mellitus. Clin Chem 2011;57:e1-e47. http://dx.doi. org/10.1373/clinchem.2010.161596.

20. Clinical and Laboratory Standards Institute. Evaluation of the linearity of quantitative measurement procedures. Ep6a. Wayne,PA, USA, 2003.

21. Jeppsson JO, Kobold U, Barr J, Finke A Hoelzel W, Hoshino T, et al. Approved IFCC reference method for the measurement of HbA1c in human blood. Clin Chem Lab Med 2002;40:7889. $h$ ttp://dx.doi.org/10.1515/CCLM.2002.016.

22. Weykamp CW, Penders TJ. Mechanism and speed of reactions between haemoglobin and glucose consequences for the measurement of glycosylated haemoglobins in patient material. Clin Chim Acta 1982;125:341- 50. http://dx.doi. org/10.1016/0009-8981(82)90265-0.

23. Lin CN, Emery TJ, Little RR, Hanson SE, Rohlfing CL, Jaisson $S$, et al. Effects of hemoglobin $C, D, E$, and $S$ traits on measurements of $\mathrm{HbA1c}$ by six methods. Clin Chim Acta 2012;413:819-21. http://dx.doi.org/10.1016/j. cca.2011.12.019.

24. Jaisson S, Leroy N, Meurice J, Guillard E, Gillery P. First evaluation of Capillarys 2 Flex Piercing ${ }^{\circledR}$ (Sebia) as a new analyzer for HbA1c assay by capillary electrophoresis. Clin Chem Lab Med 2012; 50:1769-75. http://dx.doi.org/10.1515/cclm2012-0017. 
25. Weykamp C, Waenink-Wieggers H, Kemna E, Siebelder $C$. HbA1c: performance of the Sebia Capillarys 2 Flex Piercing. Clin Chem Lab Med 2013;51:e129-31. http://dx.doi. org/10.1515/cclm-2012-0560.

26. Chapelle JP, Teixeira J, Maisin D, Assink H, Barla G, Stroobants AK, et al. Multicentre evaluation of the Tosoh $\mathrm{HbA1C}$ G8 analyser. Clin Chem Lab Med 2010;48:365-71. http:// dx.doi.org/10.1515/CCLM.2010.062.

27. Genc S, Omer B, Aycan-Ustyol E, Ince N, Bal F, Gurdol F. Evaluation of turbidimetric inhibition immunoassay (TINIA) and HPLC methods for glycated haemoglobin determination. J Clin Lab Anal 2012;26:481-5. http://dx.doi. org/10.1002/jcla.21550.

28. Heylen O, Van Neyghem S, Exterbille S, Wehlou C, Gorus F, Weets I. Evaluation of the Sebia CAPILLARYS 2 flex piercing for the measurement of $\mathrm{HbA}(1 \mathrm{c})$ on venous and capillary blood samples. Am J Clin Pathol 2014;141:867-77. http:// dx.doi.org/10.1309/AJCPRU5QC2JBANSV.

29. Marinova M, Altinier S, Caldini A, Passerini G, Pizzagalli G, Brogi M, et al. Multicenter evaluation of hemoglobin A1cassay on capillary electrophoresis. Clin Chim Acta 2013;424:207-11. http://dx.doi.org/10.1016/j.cca.2013.06.014.
30. Selvaraj N, Bobby Z, Sathiyapriya V. Effect of lipid peroxides and antioxidants on glycation of hemoglobin: an in vitro study on human erythrocytes. Clin Chim Acta 2006;366:1905. $h t t p: / / d x$. doi.org/10.1016/j.cca.2005.10.002.

31. Camargo EG, Pedrini RO, Gross JL, Camargo JL, Silveiro SP. Lack of interference of aspirin in $\mathrm{HbA1C}$ measured by ion-exchange HPLC in type 2 diabetic patients: a randomized, double-blind, placebo-controlled study. Clin Chim Acta 2008;391:120-2. http://dx.doi.org/10.1016/j. cca.2008.01.029.

32. Weykamp CW, Penders TJ, Baadenhuijsen $H$, Muskiet FA, Martina W, van der Slik W. Vitamin C and glycohemoglobin. Clin Chem 1995;41:713-6.

33. Weykamp CW, Penders TJ, Siebelder CW, Muskiet FA, van der Slik W. Interference of carbamylated and acetylated hemoglobins in assays of glycohemoglobin by HPLC, electrophoresis, affinity chromatography, and enzyme immunoassasy. Clin Chem 1998;39:138-42. 